\title{
浅谈优化国有企业人力资源效率的实践与思考 一以中交某三级公司为例
}

\section{Talking about the Practice and Thinking of Optimizing the Efficiency of Human Resources in Construction Enterprises}

\section{— Take a third-tier company in China Communications as an example}

\author{
谢 燕 \\ Yan Xie \\ 中交成都轨道交通投资建设有限公司 四川成都 610000
}

CCCC Chengdu Rail Transit Investment and Construction Co Ltd Chengdu Sichuan Province 610000

\begin{abstract}
摘 要: 本文研究的目的就在于通过分析公司人力资源现状和存在的问题,探索不断提高公司人员使用效率和员工职业生 涯得到长足发展的人力资源管理模式, 在体现公司发展的战略意图和战略目标的前提下, 实现员工满意度高、个人与组织绩 效高的人力资源管理目标, 达到吸引人才、留住人才、激励人才、发展人才的目的, 从而促进公司和人才的双向发展。最终使得 人力资源成为真正支撑公司不断发展壮大的重要战略资源与核心竞争力源泉。
\end{abstract}

\begin{abstract}
The purpose of this article is to analyze the company's human resources status and existing problems, and explore the human resource management model that continuously improves the company's personnel efficiency and employees' career development. It reflects the company's strategic intentions and strategic goals. Under the premise, to achieve the human resource management goals of high employee satisfaction and high personal and organizational performance, achieve the purpose of attracting talents, retaining talents, motivating talents, and developing talents, thereby promoting the two-way development of the company and talents. Finally, human resources have become an important strategic resource and a source of core competitiveness that truly support the company's continuous development and growth.
\end{abstract}

关键词: 建筑企业; 人力资源; 实践

Keywords : construction enterprises; human resources; practice

DOI : 10.36012/emr.v2i6.3001

\section{1.人力资源现状分析}

总体来说，“十三五”期间公司员工队伍人数变化不大， 基本维持在 1900-2000 范围内。但也存在一些波动, 其变化 趋势: 从 2015 年开始, 根据上级单位整体调整, 公司有近百 名员工被调往新成立的公司与办事处, 出现了人员减少的趋 势, 2016 年公司加大大学生引进人数, 公司目前拥有各类在 职在岗员工 1900 余名。

从人才结构上看, 公司人才结构比较合理。专业技术人 员一直是公司的最主要力量, 占所有在岗人员的 $42 \%$ 。专业 技术人员是公司的核心人员与核心竞争力的源泉, 是创造利 润的主体。专业技术人员在图纸设计、工程预算、施工技术、
项目管理等公司运作的核心环节起着中流砥柱的作用。随着 施工技术和工艺的不断进步, 劳动生产率的提高和机械化水 平的不断上升, 公司的操作技能人员比例历年减少。这说明 了我们在工程项目施工集约化的道路上又迈进了一步。

目前公司本科及以上学历的各类高学历高素质人才有 855 人, 占到 $45 \%$ 的比例。与此同时, 专科及以下学历逐年减 少; 本科及以上学历逐年大幅增长。近年来, 公司也注重引进 研究生, 同时鼓励员工攻读在职硕士研究生, 取得硕士学历 人数历年增多。同时, 人员队伍的年轻化程度越来越高, 呈现 出“年轻化”的趋势, 相当一批青年俊杰走上了公司及项目部 的管理、技术领导岗位和相关领域的骨干力量甚至是带头 人。

【作者简介】谢燕 (1988 ), 女, 安徽铜陵人, 汉族, 硕士研究生, 经济师, 研究方向: 企业人力资源管理。 
在专业技术方面, 获得高级和中级职称的人数历年增 加, 占员工总人数的比例越来越大。目前公司拥有高级职称 347 人, 中级职称 425 人。

截止目前为止, 公司高级技师只有 15 名, 而且技师和高 级工的人员数量也呈现逐年递减的趋势, 技能人才培养方 面, 与其他中交三级公司有一定的差距, 这突出了公司技能 人员培养中的问题。公司要注意技能人才的培养, 以免出现 这方面人才梯队的断层。

公司不断加强人才管理和培养制度, 加强各类人员的培 训, 先后为各类人才的发展创造了有利的环境和广阔的空 间,从而使得人才流失量逐年下降。

\section{2. 人力资源面临的问题}

\section{1 不断扩大的市场规模与人力资源相对不足的矛 盾较大}

随着国家加大基础建设的投入和我国迈人城际高铁和 城市轨道交通时代, 公司的发展也面临着新的机遇和广阔的 市场前景, 近年来公司合同中标额和年产值均不断增大, 并 且这也是今后几年发展的趋势。但员工队伍一直维持在 1900 至 2000 之间, 这一方面反映了人均产值的增加和劳动 生产率的提高, 另一方面却突出了一个问题一人力资源面 临紧张的局面。

为了弥补目前各类人力资源的不足, 使得主体员工在关 键岗位上发挥主导作用, 我们采用劳务派遣和以完成一定工 作任务为期限的劳动用工形式。用工形式的复杂化, 必然会 增加公司的用工风险, 如果我们在外聘员工管理方面不到 位, 甚至不合理、不合法, 侵犯了外聘人员的权益, 将对公司 造成不利影响。事实上,目前人力资源紧张的状况已经对我 们的人力资源管理造成了较大压力, 如何提高人力资源的使 用效率和员工的劳动生产率以适应公司不断发展的市场规 模, 是人力资源管理面临的现实课题。

\section{2 人力资源管理职能不健全导致人才培养效率不} 高。

完整的人力资源管理体系应包括: 人力资源规划、工作 分析、人才招聘、薪酬管理、绩效考核、职业生涯规划和劳动 保护等几大方面。现代人力资源管理要求具有科学性、系统 性, 各个环节衔接紧密, 是一个为人才的引进、培养和发展提 供系统有效的保障的循环。虽然公司人力资源管理的员工培 训、薪酬管理、员工管理、劳动用工、社保管理等人力资源业
务做得较为成熟。但是, 限于各方面的原因, 人力资源管理目 前还没有做到有效的人力资源规划、员工职业生涯规划,绩 效考核也是刚刚纳人正轨。而且, 薪酬设计与绩效考核的内 部联动关系也没有做好。总之, 人力资源管理的健全性和联 动性有待在实践中加强。这样人才的发展才有良好的机制保 障。

\section{3 员工培训缺乏前瞻性和创新性}

公司把对员工的培训作人力资源管理甚至经营管理的重要 组成部分。每年都要举办多次针对不同人才的各类培训。但 培训却并非都达到了预期效果。究其原因, 主要是培训理念 缺乏前瞻性, 内容单一缺乏创新性。

目前培训基本上都是依据以往的经验,在年初列出本年的培 训计划。培训计划和往年的基本没有什么差别, 都是例行性 的培训事宜。比如, 今年有多少场项目经理培训班, 什么时间 安排了技师培训班, 七月份的大学生入职培训等等。无论是 主题还是内容都大差不差,培训预算也是基本不变。培训没 有做到紧跟公司的发展变化和市场行情, 不失时机的对相关 人员展开各种类型的培训, 从而使公司的发展始终具有相关 行业人才, 甚至出现痛医头、脚痛医脚的“救火工程”。 在培训内容上,比较单一。目前公司的培训,除了项目经理培 训班等较高级的培训, 大多数培训常常停留在灌输式的教学 培训上。所请的培训师大部分是大学里相关领域的教授或者 专家, 培训内容也是预先设定好了的, 不能根据受训对象的 具体需求进行调整和完善,教学双方缺乏交流和互动。

\section{3.优化提升人力资源效率的措施}

为建立和完善与现代企业制度相匹配的人力资源管理 机制, 加大人力资源开发力度, 为公司的发展引进和培养一 批高素质人才队伍, 积极为各类专业人员提供良好的内部环 境, 激励员工成长、成才, 针对以上所列人力资源问题, 我认 为主要从以下几个方面来提高公司的人力资源效率, 从而做 到“人尽其才,才尽其用”。

\section{1 加强人力资源开发的预测研究, 制定科学合理 的人力资源规划。}

根据公司战略发展方向和业务发展规模, 以及现有的人 力资源状况, 进行人力资源开发前瞻性研究: 对本单位人力 资源总量、结构、分布以及各专业、关键岗位的人员需求进行 科学预测, 要按照本单位各专业发展的要求, 进行相关专业 纵向分析、预测, 按照各专业开发的重点、难点,结合公司发 展方向和人才成长的规律性、层次性要求, 制定科学合理人 
才需求计划, 有目的、有层次进行人才引进, 避免出现人员紧 张和人才引进的盲目性等波动较大的局面。

公司要根据所面临的形势发展和市场变化, 超前考虑、 周密安排, 制定切合实际的、科学合理的人才发展规划。要针 对“十四五”经济全球化竞争的严峻形势, 审时度势, 以培养 各类高精尖专门人才为重点, 以抓“三支队伍”, 即经营管理 人员队伍、专业技术人员队伍、技术工人队伍, 并以“三支队 伍”建设为主线, 培养一批高级决策型人才、项目管理复合人 才、专业技术人才、优秀工班长、高级技师、技师等操作型人 才, 打造一支作风过硬、结构合理、专业配套、技术精湛, 能 适应国际国内竞争需要的高素质的专业人才队伍, 以促进企 业快速、持续、健康发展。

\section{2 建立健全人力资源管理体系, 构筑有利于激发 员工成长动力的激励机制}

人力资源管理的主导思想是以“人”为中心的管理, 它围 绕着选拔合格的人才、培养合适的人才和激励优秀的人才的 目标, 通过人力资源管理各业务单元之间的相互补充和作 用, 使员工与组织共同发展。这就要求我们要做好健全的员 工岗位分析体系, 从而达到人岗匹配的效果; 建立科学的绩 效管理评价体系, 从而达到最大限度实现企业战略目标、牵 引员工发展的目的; 建立公平公正薪酬体系, 从而建立“外部 具有竞争力、内部体现公平性” 的薪酬文化; 高度重视人力资 源信息化工作, 从而提高人力资源管理的效率; 加大经营、管 理、专业技术、技能等各类专业人才开发的力度, 从而促使人 力资源结构的优化升级和整体效率的提升; 建立合理的淘汰 机制, 从而为员工成长提供公平竞争环境。

\section{3 建立切实有效的培训体系, 使得员工培训真正 成为组织效率和企业经营的重要引擎}

提升员工岗位适应性, 调动员工积极性, 发展员工的能 力是员工培训工作的重要职能。有效的培训不仅可以提高员 工的技能, 提高组织的效率, 更重要的是它可以提升企业的
核心竞争力, 促进公司业务规模的扩大, 增强企业对员工的 吸引力, 提高员工对企业的归属感。公司要改变目前的培训 思路和培训模式, 将培训融入企业的经营发展的过程, 要将 培训重点从应用型培训转到拓展型培训上来, 从填鸭式转变 到互动式上来, 从组织员工培训转变到员工主动申请培训上 来, 要把高层次人才和公司稀缺人才作为培训重点对象。

重视培训需求的分析, 要将各项培训需求与企业发展方 向、人力资源有效使用、员工发展计划相结合, 提高培训针对 性; 要加强对各类管理人员、技术人员和技能人员的培训力 度, 根据不同层次和能力的匹配策划培训方案, 明确培训目 的, 采用最适合的培训教材, 摒弃以往的单一无味的培训方 式,引进互动式案例分析、角色扮演、拓展训练、小组讨论等 形式, 加强教师与学员之间的沟通, 保证培训效果; 积极推行 培训项目负责制,将培训从项目立项、策划、实施到培训效果 评估纳入培训组织者的考核内容, 提高培训整体效益; 坚持 内、外培训结合, 利用“外脑”来拓宽思路, 提高培训层次; 培 训效果评估要建立在培训前后对比的基础上,定期考察学员 对知识、技能的应用及业绩的改善情况, 提升培训质量; 在培 训方式上,要注重效益、质量,因材施教,因人而异, 针对不同 的人才采取相应的培训措施, 围绕突出重点、主动开发的原 则, 为企业培养一批在各个专业具有竞争力的员工。

\section{4.结语}

总而言之, 我们要不断提升公司的人力资源管理水平, 做到人力资源管理的一切业务职能都是切实有效的为人才 的培养和发展服务的。同时我们的工作目标也是在公司的经 营发展中不断地追求“人尽其才, 才尽其用”的理想境界, 从 而达到企业长远发展和个人不断成长的双赢目标, 做到真正 意义上的“以人为本”!

\section{参考文献:}

[1] 张文娟.对国有建筑企业人力资源管理的几点思考[J].西部探矿 工程, 2004, (9).

\section{(上接第 31 页)}

\section{4. 结束语}

总而言之, 目前电子商务企业会计工作开展过程中, 仍 然存在着各种各样的问题,多方面因素阻碍了会计工作质量 水平的提升, 对企业各方面的全面发展也产生了不利影响, 在今后工作中, 企业要加强对问题的研究分析, 将其不断解 决, 总结工作经验来促进日后会计工作的转型升级, 进一步
的带动企业的可持续发展。

\section{参考文献}

[1] 李文佳. 我国企业风险管理审计存在的问题及对策探析[D]. 江 西财经大学, 2019.

[2] 舒潼.我国公允价值审计存在的问题及对策[D].江西财经大学, 2018. 